\title{
Inorganic-Organic Hybrids Based on Poly ( $\varepsilon$-Caprolactone) and Silica Oxide and Characterization by Relaxometry Applying Low-field NMR
}

\author{
Mariana Sato de Souza de Bustamante Monteiro, Roberto Pinto Cucinelli Neto, \\ Izabel Cristina Souza Santos, Emerson Oliveira da Silva, Maria Inês Bruno Tavares* \\ Instituto de Macromoléculas Professora Eloisa, Centro de Tecnologia, \\ Universidade Federal do Rio de Janeiro - UFRJ, Bloco J, Cidade Universitária, \\ Ilha do Fundão, CP 68525, CEP 21945-970, Rio de Janeiro, RJ, Brasil
}

Received: March 19, 2012; Revised: May 8, 2012

\begin{abstract}
Poly ( $\varepsilon$-caprolactone) (PCL) based hybrids containing different amounts of modified (Aerosil ${ }^{\circledR}$ R972) and unmodified (Aerosil ${ }^{\circledR}$ A200) silica oxide were prepared employing the solution method, using chloroform. The relationships of the amount of nanofillers, organic coating, molecular structure and intermolecular interaction of the hybrid materials were investigated mainly using low-field nuclear magnetic resonance (NMR). The NMR analyses involved the hydrogen spin-lattice relaxation time $\left(\mathrm{T}_{1} \mathrm{H}\right)$ and hydrogen spin-lattice relaxation time in the rotating frame $\left(\mathrm{T}_{1} \rho \mathrm{H}\right)$. The spin-lattice relaxation time measurements revealed that the PCL/silica oxide hybrids were heterogeneous, meaning their components were well dispersed. X-ray diffraction (XRD), differential scanning calorimetry (DSC) and thermogravimetric analysis (TGA) were also employed. The DSC data showed that all the materials had lower crystallization temperature (Tc) and melting temperature (Tm), so the crystallinity degree of the PCL decreased in the hybrids. The TGA analysis demonstrated that the addition of modified and unmodified silica oxide does not cause considerable changes to PCL's thermal stability, since no significant variations in the maximum temperature (Tmax) were observed in relation to the neat polymer.
\end{abstract}

Keywords: polycaprolactone, silica oxide, hybrids, nuclear magnetic resonance

\section{Introduction}

Organic/inorganic hybrid materials have been attracting much attention since they can combine the advantages of inorganic materials with the properties of organic polymers $^{1,2}$. When inorganic phases in organic/inorganic composites have nanosize, they are called nanocomposites. Moreover, the uniform dispersion of these nanofillers produces a large interfacial region between the nanofiller and polymer due to their high specific surface area, leading to peculiar characteristics of polymer based nanostructure materials $^{3-5}$.

These hybrids can be prepared by various synthesis routes. The organic component can be introduced as (i) a precursor, which can be a monomer or an oligomer, (ii) a preformed linear polymer, or (iii) a polymer network, physically or chemically cross-linked. The inorganic part can be introduced as (i) a precursor or (ii) preformed particles. This leads to three general methods for preparing polymer/silica oxide nanocomposites, according to the desired materials to be obtained and processing techniques, namely: blending, sol-gel processing and in situ polymerization ${ }^{6}$.

Solution blending is a liquid-state powder processing method that produces good mixing at the molecular level.

*e-mail: mibt@ima.ufrj.br
It is widely used in material preparation and processing. The polymer and nanoparticles are dissolved or dispersed in solution 6 .

Polycaprolactone is a linear semicrystalline polyester ( $\sim 50 \%$ crystallinity), characterized by a relatively low glass transition temperature $\left(\sim 60^{\circ} \mathrm{C}\right)$, and is produced by the ring opening polymerization of $\varepsilon$-caprolactone. It is a biocompatible and biodegradable polymer, degradable either through hydrolytic or enzymatic cleavage along the macromolecular chain. Its potential uses are currently being examined as biodegradable packaging materials, controlled drug release carriers and other medical applications such as suture filaments. The main disadvantages of PCL are its low melting temperature $\left(\sim 60{ }^{\circ} \mathrm{C}\right)$, modulus and abrasion resistance, as well as its relatively high $\operatorname{cost}^{7-9}$.

The incorporation of nanofillers, such as silica oxide, in a polymeric matrix can improve the properties of nanocomposites, such as dimensional stability. The main objective of this work was to obtain PCL/silica oxide hybrids by solvent casting with modified (Aerosil ${ }^{\circledR}$ R972) and unmodified silica oxide (Aerosil ${ }^{\circledR}$ A200). The other objective was to investigate the crystallization and thermal behavior of hybrids containing different amounts of silica oxide, through differential scanning calorimetry and thermogravimetric analysis, and to relate such behavior to the morphology, 
revealed by X-ray diffraction and low field NMR, to shed light on the characteristics of these heterogeneous materials.

NMR offers a great variety of relaxation times, which can provide good information about the interface interaction between composite components and the inorganic particle dispersion. This can be obtained using low-field NMR, which permits measuring the proton spin-lattice relaxation time, $\mathrm{T}_{1} \mathrm{H}$, and proton spin-lattice relaxation time in the rotating frame, $\mathrm{T}_{1} \rho \mathrm{H}$, of the materials. These sample analyses enable the identification of the molecular motions, domain formation, phase separation and intermolecular interaction, all of which promote changes in the proton relaxation times. This feature makes the technique a good tool to analyze the molecular dynamics of polymer systems and materials, especially nanocomposite materials ${ }^{10-16}$.

\section{Material}

Polycaprolactone (PCL) Mn = 80,000 was supplied by Sigma Aldrich. Hydrophilic silica oxide particles and organo silica oxide nanoparticles were supplied by Degussa AG, named Aerosil ${ }^{\circledR}$ A200 and Aerosil ${ }^{\circledR}$ R972, respectively. The hydrophilic silica oxide particles have a specific surface area of $200 \mathrm{~m}^{2} . \mathrm{g}^{-1}$ and an average primary particle size of $12 \mathrm{~nm}$ and the hydrophobic silica has a specific surface area of $170 \mathrm{~m}^{2} \cdot \mathrm{g}^{-1}$ and an average primary particle size of $12 \mathrm{~nm}$.

\section{Preparation of PCL/silica Oxide Hybrids}

The PCL/silica hybrids were prepared using the solvent casting technique, which promotes good nanoparticle dispersion, using $\mathrm{CHCl}_{3}$ as the solvent, chosen according to the PCL's solubility ${ }^{17}$.

The solutions of PCL and hydrophobic silica oxide were stirred separately at room temperature for 24 hours to prepare the nanomaterials with different silica oxide ratios. The silica oxide dispersions were subjected to ultrasound for one hour. After that, the dispersions were mixed and stirred for 48 hours at room temperature. The resulting mixture was put onto plates, covered and kept at room temperature to eliminate the solvent slowly. After that, the hybrid films were dried under vacuum for 48 hours and all samples were stored in desiccators before being analyzed. For comparison, nanomaterials formed by PCL/unmodified silica oxide with the same silica oxide ratios were prepared under the same experimental conditions.

\section{Characterization Techniques}

\subsection{FTIR analysis}

The infrared spectra were obtained by using a Nicolet Magna FR 760 FTIR spectrometer. The samples were investigated by depositing the films from the solution. The spectra were recorded at room temperature using 64 scans at $2 \mathrm{~cm}^{-1}$ resolution from 200 to $4000 \mathrm{~cm}^{-1}$.

\subsection{X-ray diffraction}

The hybrid films were investigated by X-ray diffraction (XRD) using a Rigaku D/max 2400 diffractometer, with nickel-filtered $\mathrm{CuK} \alpha$ radiation at a wavelength of $1.54 \AA$, at room temperature. The $2 \theta$ scanning range was varied from $2^{\circ}$ to $30^{\circ}$, with a step of 0.02 , operated at $40 \mathrm{KV}$ and $30 \mathrm{~mA}$.

\subsection{NMR relaxation method}

\subsubsection{Spin-lattice relaxation times}

All measurements of spin-lattice relaxation times $\left(\mathrm{T}_{1} \mathrm{H}\right.$ and $\mathrm{T}_{1} \rho \mathrm{H}$ ) were performed using a Resonance Instruments Maran Ultra 23 low-field NMR spectrometer operating at $23.4 \mathrm{MHz}$ (for protons), equipped with an $18 \mathrm{~mm}$ variable temperature probe. The pulse sequence used for $\mathrm{T}_{1} \mathrm{H}$ determination was inversion-recovery (recycle delay $180^{\circ}-\tau-90^{\circ}$ acquisition). The $90^{\circ}$ pulse, $4.6 \mu \mathrm{s}$, was calibrated automatically by the instrument's software. The amplitude of the FID was sampled for $20 \tau$ data points, ranging from 0.1 to $5000 \mathrm{~ms}$, with four scans each and 5 seconds of recycle delay. The temperature was $25^{\circ} \mathrm{C}$. The $\mathrm{T}_{1} \mathrm{H}$ values and relative intensities were obtained by fitting the exponential data with the aid of the WINFIT program. Distributed exponential fitting of plots of relaxation amplitude versus relaxation time were performed by using the WINDXP software. The ${ }^{1} \mathrm{H} \mathrm{T}_{1} \rho$ values were measured with ordinary spin-lock pulse sequencing, which was $90^{\circ} \mathrm{x}$-(spin-lock pulse) $\mathrm{y}$-(acquisition). The amplitude of the FID was sampled for $32 \tau$ data points, ranging from 25 to $100,000 \mu \mathrm{s}$, with four scans each and $5 \mathrm{~s}$ of recycle delay. The $T_{1} \rho$ values and relative intensities were obtained also by fitting the exponential data with the aid of the WINFIT program and the distributed exponential fitting of plots of relaxation amplitude versus relaxation time was performed by using the WINDXP software. The spin-lock field was $12.5 \mathrm{kHz}$.

Equation 1 was used to calculate the $\mathrm{T}_{1} \rho$ values:

$y=y_{0}+A_{i e}^{-(x-x 0) / t 1}$

- $y-$ total magnetization intensisty;

- $\mathrm{y}_{0}$-intensity of the magnetization at the initial time;

- Ai - constant time;

- $\mathrm{X}$ - signal weight at the initial point;

- $\mathrm{X}_{0}$ - signal weight at the initial time; and

- $\mathrm{t} 1$ - time interval between $180^{\circ}$ and $90^{\circ}$ pulses

\subsection{Thermal analysis}

The thermal properties of the PCL and its hybrids were investigated using a Rigaku TAS 100 differential scanning calorimeter. Dry nitrogen gas was used as carrier gas at a flow rate of $20 \mathrm{~mL} / \mathrm{min}$. The DSC curves were recorded between $-70{ }^{\circ} \mathrm{C}$ and $150{ }^{\circ} \mathrm{C}$, with a heating rate of $10^{\circ} \mathrm{C} / \mathrm{min}^{-1}$. The fraction $\mathrm{Xc} \%$ of material crystallized after an interval, $\mathrm{t}$, was evaluated by the ratio of the crystallization area at time, t, over the total area, according to Equation 2, and the crystallinity degrees $(\mathrm{Xc})$ were determined by measuring the enthalpy of fusion of the PCL in the crystalline state, using the literature datum of $139.6 \mathrm{Jg}^{-1[18]}$.

$X_{c}=\frac{\Delta H_{f}}{\Delta H_{100 \%}} \times 100$

The thermogravimetric analysis was carried out in a TA Instruments Q500 apparatus, operating from 25 to $500{ }^{\circ} \mathrm{C}$ under nitrogen flow of $50 \mathrm{~mL} / \mathrm{min}$, at a heating rate of $10^{\circ} \mathrm{C} / \mathrm{min}$. 


\section{Results and Discussion}

\subsection{Hybrids' structural characterization}

The chemical structure of the polymer/silica oxide hybrids can be generally identified by FTIR. Consequently, this technique is widely used to establish the formation of new materials. In addition, far infrared analysis is useful for inorganic studies since the stretching vibrations and angular deformation between organic/inorganic compounds occurs at frequencies lower than $650 \mathrm{~cm}^{-1[19]}$.

The FTIR spectra of the Aerosil ${ }^{\circledR}$ R972 and Aerosil ${ }^{\circledR}$ A200 (Figure 1) showed an absorption peak at about $1100 \mathrm{~cm}^{-1}$, attributed to the asymmetric stretching vibrations of the Si-O-Si bonds of silica oxide, while the peak at $820 \mathrm{~cm}^{-1}$ can be attributed to the symmetric deformation of the Si-O-Si bonds. These are typical absorption bands for Si-O-Si network vibrations ${ }^{6,20}$. In Figure 1, the two narrow peaks located at 2870 and $2954 \mathrm{~cm}^{-1}$ are attributed to $\mathrm{C}-\mathrm{H}$ stretching vibration of the PCL's hydrocarbon and the narrow peak centered at $1734 \mathrm{~cm}^{-1}$ is derived from the stretching vibration of the PCL's carbonyl groups $(\mathrm{C}=\mathrm{O})^{21,22}$.

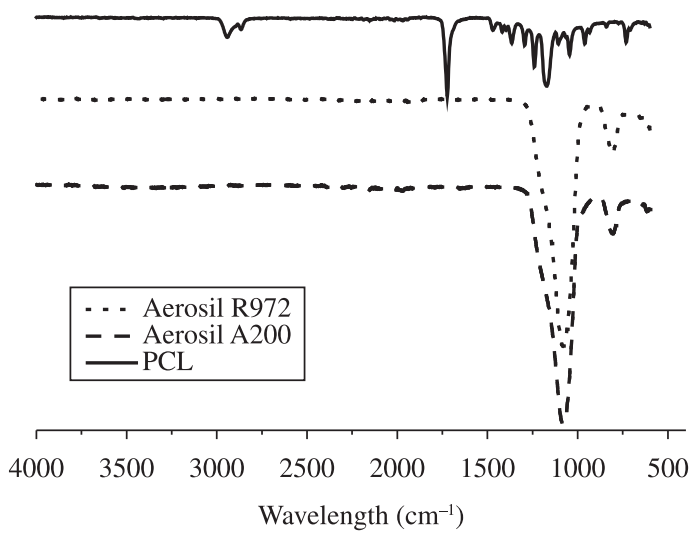

Figure 1. FTIR spectra of modified (Aerosil ${ }^{\circledR}$ R972) and unmodified (Aerosil ${ }^{\circledR}$ A200) silica oxide.

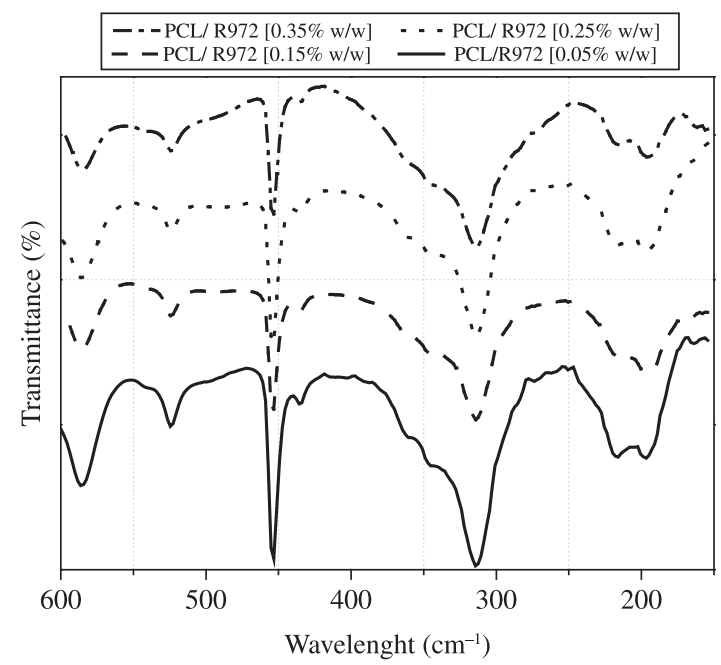

The FTIR spectra of the hybrids formed by silica, PCL/Aerosil $^{\circledR}$ R972 and PCL/Aerosil ${ }^{\circledR}$ A200 silica oxide (Figure 2) present the characteristic peaks of silica oxide in the far infrared region. The peak at about $464 \mathrm{~cm}^{-1}$ is attributed to the vibration of $\mathrm{O}-\mathrm{Si}-\mathrm{O}$ bonds ${ }^{19,23}$. According to the literature, silica oxide has a characteristic peak located at $370 \mathrm{~cm}^{-1[23]}$. Therefore, this peak was displaced to the $345 \mathrm{~cm}^{-1}$ region in the PCL/silica oxide hybrids. In addition, this peak becomes broader with increasing silica oxide ratio, indicating binding with PCL and silica oxide ${ }^{3,6}$. The peak located at about $750 \mathrm{~cm}^{-1}$ (see Figure 1) is attributed to the bending vibrations of $\mathrm{Si}-\mathrm{O}-\mathrm{Si}$ and was sharper in the hybrids prepared with modified silica oxide (Figure $3 \mathrm{a})^{21}$.

The FTIR spectra of the hybrids (Figure 3) showed vibrations at $3500 \mathrm{~cm}^{-1}$, which can be attributed to the stretching of the silica oxide hydroxyl groups and also the remaining, adsorbed water molecules ${ }^{23}$. The hydroxyl groups at the surface have potential to form hydrogen-bonding interactions with the carbonyls of the PCL chains ${ }^{21}$. These infrared spectroscopic results indicate the occurrence of binding between the PCL chain and modified silica oxide.

The hybrid materials were submitted to wide-angle $\mathrm{X}$-ray diffraction measurement. The XRD curves are shown in Figure 4. The XRD technique is based on the elastic scattering of $\mathrm{X}$-rays from structures that have long-range order. It is an efficient analytical technique to identify and characterize crystalline materials. The X-ray diffraction results showed that silica oxide nanoparticles are predominantly amorphous ${ }^{6}$. The strong and sharp crystalline peaks located at $21.3^{\circ}$ and $23.8^{\circ}$ are attributed to the [110] and [200] crystallographic planes of the PCL crystal, respectively ${ }^{24}$. Analysis of the PCL/Aerosil ${ }^{\circledR}$ R972 hybrid materials showed that the crystallization degree of the PCL matrix did not change. However, the intensity of the diffraction peaks in the PCL/Aerosil ${ }^{\circledR}$ A200 hybrids were significantly lower. The broad amorphous halos were stronger in the PCL/Aerosil ${ }^{\circledR}$ R972 hybrids than in the PCL/Aerosil ${ }^{\circledR}$ A200 hybrids, suggesting formation of materials with lower crystallinity degree ${ }^{21}$.

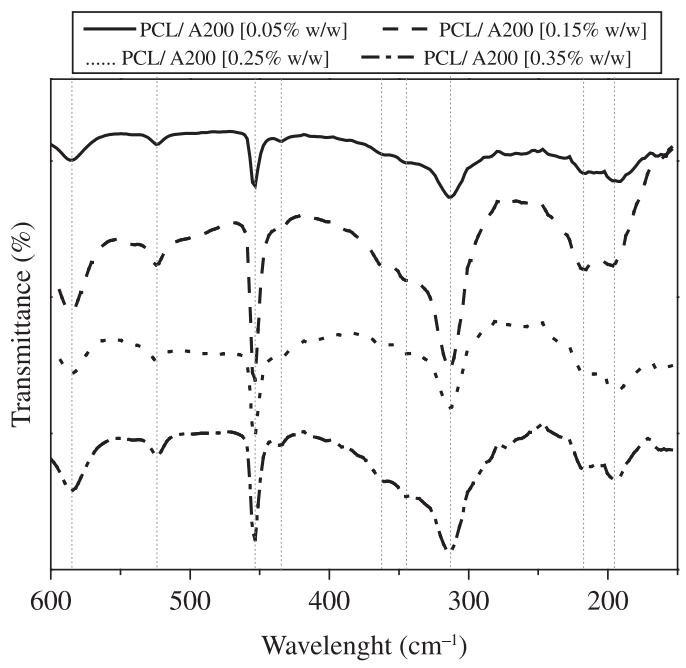

Figure 2. The far FTIR spectra of PCL/Aerosil ${ }^{\circledast}$ R972 hybrids (a) and PCL/Aerosi ${ }^{\circledast}$ A200 hybrids (b). 


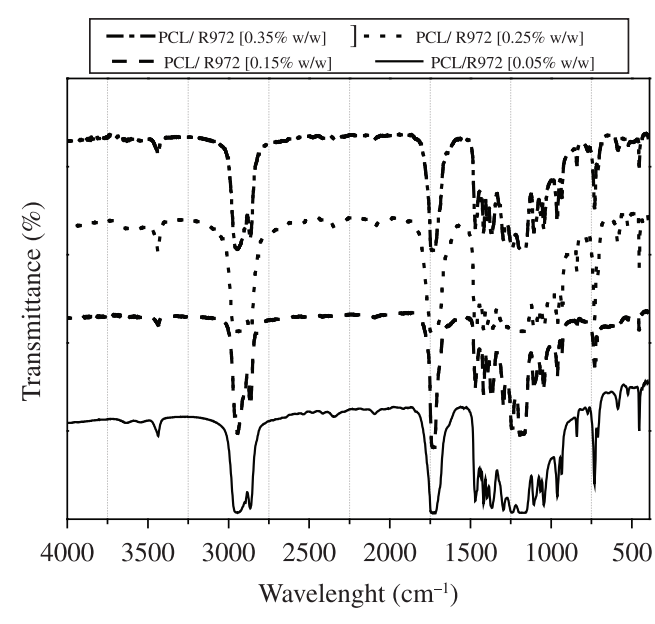

(a)

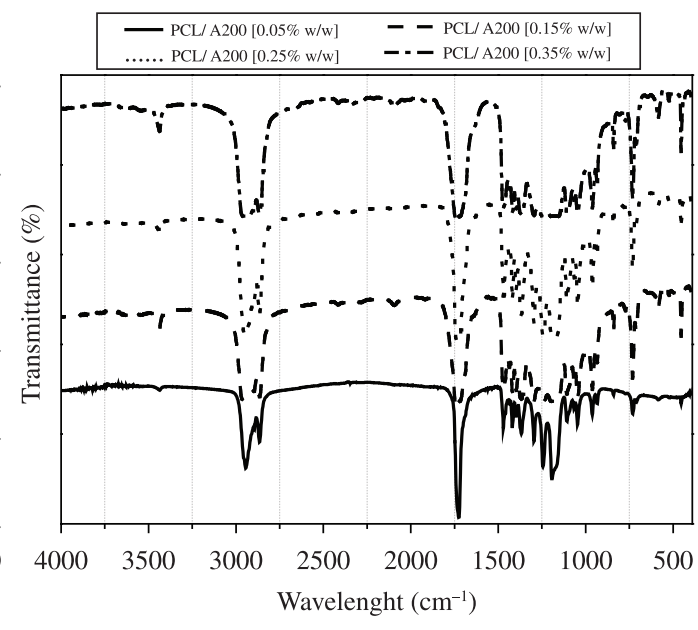

(b)

Figure 3. The FTIR spectra of PCL/Aerosil ${ }^{\circledR}$ R972 hybrids (a) and PCL/Aerosil ${ }^{\circledR}$ A200 hybrids (b).
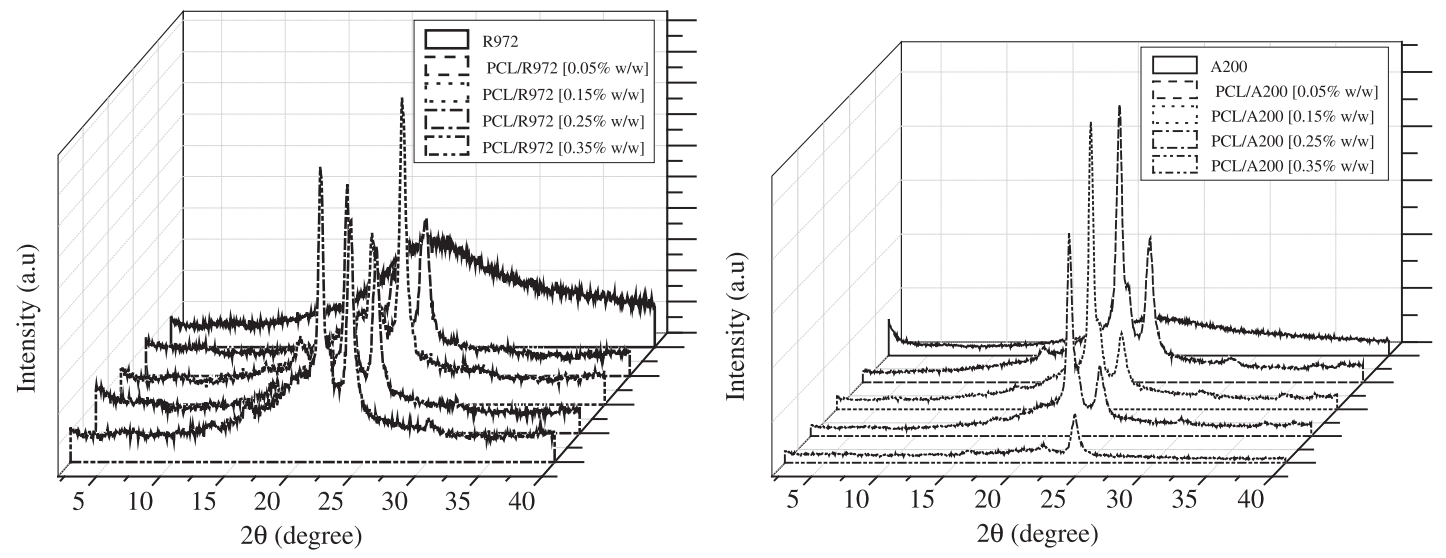

Figure 4. XRD curves of PCL/Aerosil ${ }^{\circledR}$ R972 hybrids and PCL/Aerosil ${ }^{\circledR}$ A200 hybrids, respectively.

\subsection{Thermal analysis}

The thermal parameters such as melting point, crystallization temperature and crystallinity degree were determined from DSC analyses, and the results are shown in Table 1.

Figure 4 and Table 1 show that the addition of modified and unmodified silica oxide hinders the cold crystallization process by drastically lowering the related enthalpy of crystallization $(\Delta \mathrm{Hc})$. Furthermore, significant features can also be detected in the melting signal, which is also characterized by relatively low enthalpy.

The systems showed a decrease in the $\Delta \mathrm{Hc}$ and $\Delta \mathrm{Hm}$, which could be related to a restriction in the PCL crystallization kinetics. Probably the multiple interaction formed in the organic-inorganic hybrids causes a highly restricted segmental motion, hindering crystallization ${ }^{25,26}$.

A reduction in the crystallinity of the PCL matrix in the hybrid materials in the presence of silica oxide nanoparticles compared to the PCL (Table 1) was observed. The decrease in the crystallinity degree can be attributed to the PCL's interaction with the silica oxide nanoparticles. According to the literature ${ }^{3}$, the polyester chains linked to the silica oxide surface can reduce the PCL chain mobility. In this work, this effect was stronger for the PCL/Aerosil ${ }^{\circledR}$ R972 hybrids, because the silica oxide surface modifier particles promote an increase in the affinity of silica oxide with the polymeric matrix.

The thermal degradation stability of the hybrid samples was studied through the determination of their weight loss due to the formation of volatile degradation products as a function of temperature in an inert atmosphere. Figure 5 shows the weight loss for all the samples studied.

The thermal degradation of PCL in an inert atmosphere takes place through the rupture of the polyester chains through ester pyrolysis reaction, with the release of $\mathrm{CO}_{2}$ and $\mathrm{H}_{2} \mathrm{O}$ and the formation of carboxylic acid groups. Pyrolysis promotes chain cleavages randomly distributed along the chain and when two pyrolysis reactions occur with ester functions, one of the reaction products is 5-hexenoic $\operatorname{acid}^{23,27,28}$.

The thermogravimetric curves showed that the PCL and samples with different silica oxide presented relatively good thermal stability, since no substantial weight loss occurred up to $300^{\circ} \mathrm{C}$. The addition of modified and unmodified silica oxide did not cause considerable changes in PCL thermal stability, as no significant variations in Tmax were observed with respect to the PCL (Table 2). 
Generally speaking, the incorporation of nanosized inorganic particles into a polymer matrix enhances its thermal stability by acting as a mass transport barrier to the volatile products generated during decomposition. On the other hand, the incorporation of nanosized inorganic particles, such as silica oxide, reduces the thermal stability of the hybrid samples at lower temperatures. The thermal stability of PCL hybrids depends on the silica oxide incorporation and dispersion into the PCL matrix, which in turn depends on the PCL's molecular weight and the reactivity of its functional groups ${ }^{6,29,30}$.

\subsection{NMR analysis}

The influence of silica oxide on the PCL matrix, with relation to the molecular dynamic, was evaluated by nuclear relaxometry, using low-field nuclear magnetic resonance.

To better investigate the compatibility, dispersion and interaction between both hybrid components, proton spin-lattice relaxation time (Table 3 ) and proton spin-lattice relaxation time in the rotating frame (Table 4) were determined in a low-field NMR spectrometer ${ }^{31}$. The influence of silica oxide dispersion in the PCL crystalline phase was also investigated.

According to the results of $\mathrm{T}_{1} \mathrm{H}_{\mathrm{PCL}}$ film listed in Table 3, it presents two spin populations that relax at approximately $30 \mathrm{~ms}(21 \%)$ and $142 \mathrm{~ms}$ (79\%), corresponding to the mobile region (amorphous) and constricted amorphous/crystalline

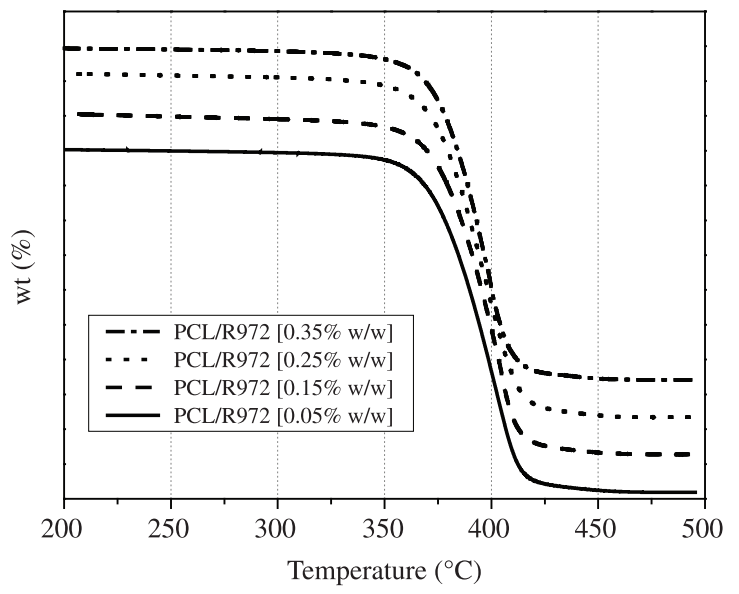

(a) domains, respectively. According to this result, at least two types of molecular organization structure occurred in this semicrystalline polymer (Table 3 ). One was derived from the amorphous phase, whose protons had shorter relaxation time, and the second one referred to the protons that are constricted in the crystalline and/or rigid phase, which had longer relaxation times ${ }^{32}$.

The spin-lattice relaxation time measurements revealed that the PCL-silica oxide hybrids were heterogeneous, as expected. However, their components were well dispersed. This can be explained by the values of spin-lattice relaxation times, which are near those of the PCL matrix. It was clear that the relaxation times changed due to the interaction between both hybrid components and the silica oxide dispersion in the PCL matrix. It was also observed that the silica oxide ratio influences its dispersion and distribution in the polymer matrix.

According to the $\mathrm{T}_{1} \mathrm{H}$ values shown in Table 3, the hybrid materials prepared with Aerosil ${ }^{\circledR} \mathrm{R} 972$ (organo modified) presented good component dispersion and compatibility, since the $\mathrm{T}_{1}$ values are lower than those found for the hybrids prepared with Aerosil ${ }^{\circledR}$ A200 (unmodified). This behavior can be attributed to the interfacial interaction strength between components in the hybrid materials prepared with modified silica oxide nanoparticles. However, in the PCL/Aerosi $1{ }^{\circledR}$ A200 $[0.15 \% \mathrm{w} / \mathrm{w}]$, the components did not interact well, due to the decrease in the $\mathrm{T}_{1}$ below the PCL value. This result can

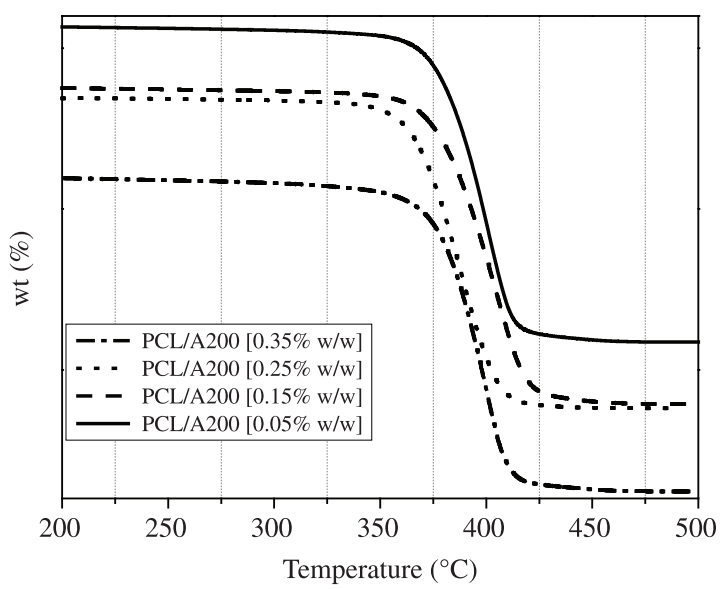

(b)

Figure 5. TGA curves for PCL/Aerosil ${ }^{\circledR}$ R972 hybrids (a) and PCL/Aerosil ${ }^{\circledR}$ A200 hybrids (b).

Table 1. DSC data for PCL, PCL/silica oxide hybrids containing unmodified and modified silica oxide.

\begin{tabular}{cccccc}
\hline Samples & DHc $\left(\mathbf{J . g}^{-1}\right)$ & $\mathbf{T c} \pm \mathbf{1}\left({ }^{\circ} \mathbf{C}\right)$ & $\mathbf{T m} \pm \mathbf{1}\left({ }^{\circ} \mathbf{C}\right)$ & $\mathbf{D H m}\left(\mathbf{J . g} \mathbf{g}^{-\mathbf{1}}\right)$ & $\mathbf{X c}(\boldsymbol{\%})$ \\
\hline PCL & 71.1 & 33 & 53 & 73.4 & 52.6 \\
PCL/A200 [0.05\% w/w] & 57.2 & 23 & 55 & 58.8 & 42.2 \\
PCL/A200 [0.15\% w/w] & 54.5 & 22 & 57 & 55.9 & 40.1 \\
PCL/A200 [0.25\% w/w] & 61.3 & 24 & 55 & 61.9 & 44.5 \\
PCL/A200 [0.35\% w/w] & 58.6 & 23 & 54 & 57.8 & 41.5 \\
PCL/R972 [0.05\% w/w] & 54.8 & 20 & 56 & 50.1 & 36.0 \\
PCL/R972 [0.15\% w/w] & 54.8 & 18 & 56 & 51.6 & 37.0 \\
PCL/R972 [0.25\% w/w] & 55.2 & 22 & 56 & 56.1 & 40.3 \\
PCL/R972 [0.35\% w/w] & 52.8 & 19 & 55 & 53.8 & 38.5 \\
\hline
\end{tabular}


be attributed to the poor dispersion of unmodified silica oxide in the PCL matrix. However, for all hybrid ratios, the rigid domain, which has the highest relaxation parameter value, controls the relaxation process ${ }^{31-33}$.

Table 2. Thermal parameters, determined by TGA, for PCL and PCL hybrids containing unmodified and modified silica oxide.

\begin{tabular}{cc}
\hline Samples & $\mathbf{T m a x}\left({ }^{\circ} \mathbf{C}\right) \pm \mathbf{1}{ }^{\circ} \mathbf{C}$ \\
\hline PCL & 409 \\
PCL/A200 [0.05\% w/w $]$ & 401 \\
PCL/A200 [0.15\% w/w $]$ & 406 \\
PCL/A200 [0.25\% w/w] & 392 \\
PCL/A200 [0.35\% w/w $]$ & 400 \\
PCL/R972 [0.05\% w/w $]$ & 407 \\
PCL/R972 [0.15\% w/w $]$ & 409 \\
PCL/R972 [0.25\% w/w $]$ & 401 \\
PCL/R972 [0.35\% w/w $]$ & 400 \\
\hline
\end{tabular}

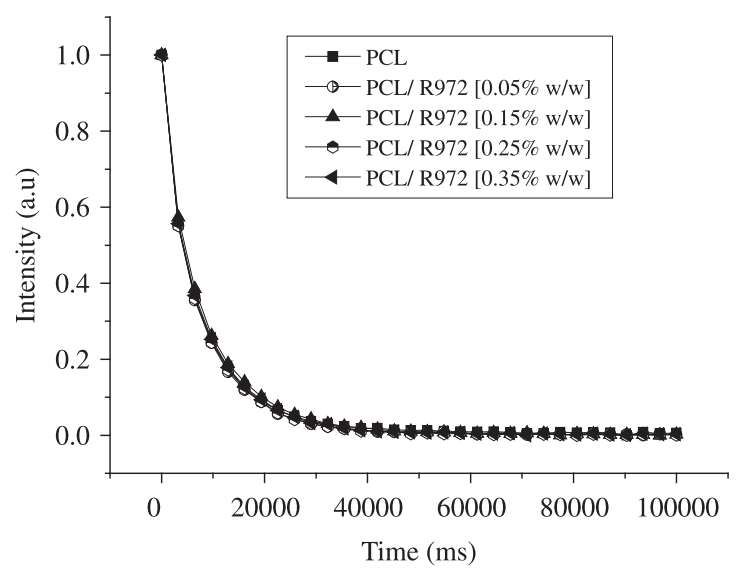

(a)
The proton $\mathrm{T}_{1} \rho \mathrm{H}$ was determined to evaluate the changes in the nanostructure and molecular mobility in the polymeric hybrids. This parameter also permits verification of the homogeneity of polymer systems, as it is sensitive to the chains' spatial proximity. The $\mathrm{T}_{1} \rho \mathrm{H}$ value represents the average of the proton molecular mobility of the PCL matrix chains in each sample. Generally speaking, for well dispersed hybrids, just one value of this parameter is found. More than one value is an indication that at least two domains with distinct motilities are present due to the formation of non-homogeneous material ${ }^{34,35}$. Hybrid materials are essentially heterogeneous due to their initial components being organic-inorganic. So, more than one $\mathrm{T}_{1} \rho \mathrm{H}$ value is expected, since the domains' size detected from this parameter varies from 4 to $25 \mathrm{~nm}$. Therefore, if a hybrid material presents good dispersion and good distribution of the nanoparticles, it will have one domain.

Table 4 shows the $\mathrm{T}_{1} \rho \mathrm{H}$ values for the PCL chain and PCL/silica oxide hybrids prepared. Figure 6 shows the $\mathrm{T}_{1} \rho \mathrm{H}$ curves with one fit, for PCL/Aerosil ${ }^{\circledR} \mathrm{R} 972$ and

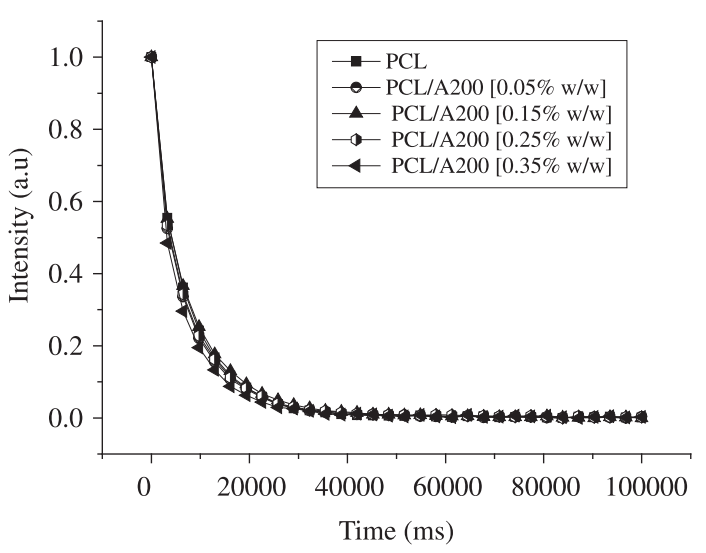

(b)

Figure 6. $\mathrm{T}_{1} \rho \mathrm{H}$ decay for PCL/Aerosil ${ }^{\circledR} \mathrm{R} 972$ (a) and PCL/Aerosil ${ }^{\circledR} \mathrm{A} 200$ (b).

Table 3. Proton spin-lattice values of PCL and PCL/silica oxide hybrids measured by low-field NMR.

\begin{tabular}{|c|c|c|c|}
\hline Samples & $\mathrm{T}_{1} \mathrm{H}$ one $\exp (\mathrm{ms})$ & $\mathrm{T}_{1} \mathrm{H}$ two $\exp (\mathrm{ms})$ & Intensity (\%) \\
\hline \multirow{2}{*}{ PCL } & \multirow{2}{*}{106} & 30 & 21 \\
\hline & & 142 & 79 \\
\hline \multirow{2}{*}{ PCL/A200 $[0.05 \% \mathrm{w} / \mathrm{w}]$} & \multirow{2}{*}{120} & 24 & 15 \\
\hline & & 153 & 85 \\
\hline \multirow{2}{*}{ PCL/A200 [0.15\% w/w $]$} & \multirow{2}{*}{123} & 25 & 15 \\
\hline & & 157 & 85 \\
\hline \multirow{2}{*}{ PCL/A200 [0.25 w/w $]$} & \multirow{2}{*}{121} & 20 & 13 \\
\hline & & 149 & 87 \\
\hline \multirow{2}{*}{ PCL/A200 $[0.35 \% \mathrm{w} / \mathrm{w}]$} & \multirow{2}{*}{104} & 27 & 20 \\
\hline & & 148 & 75 \\
\hline \multirow{2}{*}{ PCL/R972 [0.05 w/w] } & \multirow{2}{*}{115} & 23 & 15 \\
\hline & & 142 & 85 \\
\hline \multirow{2}{*}{ PCL/R972 [0.15 w/w] } & \multirow{2}{*}{116} & 24 & 15 \\
\hline & & 148 & 85 \\
\hline \multirow{2}{*}{ PCL/R972 [0.25 w/w] } & \multirow{2}{*}{118} & 22 & 15 \\
\hline & & 146 & 85 \\
\hline \multirow{2}{*}{ PCL/R972 [0.35 w/w] } & \multirow{2}{*}{116} & 22 & 15 \\
\hline & & 145 & 85 \\
\hline
\end{tabular}


Table 4. $\mathrm{T}_{1} \rho \mathrm{H}$ values of PCL/Aerosil ${ }^{\circledR} \mathrm{R} 972$ and PCL/Aerosil ${ }^{\circledR} \mathrm{A} 200$.

\begin{tabular}{cc}
\hline Samples & $\mathbf{T}_{1} \rho \mathbf{H}(\mathbf{m s})$ \\
\hline PCL & $6.7 \pm 0.2$ \\
PCL/A200 $[0.05 \% \mathrm{w} / \mathrm{w}]$ & $6.2 \pm 0.2$ \\
PCL/A200 $[0.15 \% \mathrm{w} / \mathrm{w}]$ & $6.9 \pm 0.2$ \\
PCL/A200 $[0.25 \% \mathrm{w} / \mathrm{w}]$ & $6.3 \pm 0.2$ \\
PCL/A200 $[0.35 \% \mathrm{w} / \mathrm{w}]$ & $5.4 \pm 0.1$ \\
PCL/R972 [0.05\% w/w $]$ & $6.6 \pm 0.1$ \\
PCL/R972 $[0.15 \% \mathrm{w} / \mathrm{w}]$ & $7.2 \pm 0.2$ \\
PCL/R972 $[0.25 \% \mathrm{w} / \mathrm{w}]$ & $6.7 \pm 0.1$ \\
PCL/R972 $[0.35 \% \mathrm{w} / \mathrm{w}]$ & $6.9 \pm 0.2$ \\
\hline
\end{tabular}

PCL/Aerosil ${ }^{\circledR}$ A200. The $\mathrm{T}_{1} \rho \mathrm{H}$ curves show the same shapes. Their fits gave a similar value of this parameter for all samples except for PCL/A200 [0.35\% w/w], which presented lower relaxation values for this parameter. This decline is an indication that this sample had good intermolecular interaction between the polymer matrix and silica oxide, due to the greater proximity of the hybrid components, promoting formation of more rigid material due to a better dispersion of the silica oxide particles. The proximity of the proton spin-lattice relaxation times in the rotating frame for the hybrid materials suggests that the intermolecular dipole-dipole interactions between polymer

\section{References}

1. Ochi M, Takahashi R and Terauchi R. Phase structure and mechanical and adhesion properties of epoxy/silica hybrids. Polymer. 2001; 42:5151-5158. http://dx.doi.org/10.1016/ S0032-3861(00)00935-6

2. Zou J, Shi W and Hong X. Characterization and properties of a novel organic-inorganic hybrid based on hyperbranched aliphatic polyester prepared via sol-gel process. Composites Part A: Applied Science and Manufacturing. 2005; 36:631-637. http://dx.doi.org/10.1016/j.compositesa.2004.08.001

3. Avella M, Bondioli F, Cannello V, Di Pace E, Errico ME, Ferrari AM et al. Poly( $\varepsilon$-caprolactone)-based nanocomposites: Influence of compatibilization on properties of poly( $\varepsilon$-caprolactone)-silica nanocomposites. Composites Science and Technology. 2006; 66:886-894. http://dx.doi. org/10.1016/j.compscitech.2005.08.014

4. Avella M, Bondioli F, Cannello V, Cosco S, Errico ME, Ferrari AM et al. Properties/Structure Relationships in Innovative PCL-SiO ${ }_{2}$ Nanocomposites. Macromolecular Symposia. 2004; 218:201-210.

5. Xu GC, Li AY, Zhang LD, Yu XY, Xie T and Wu GS. Nanomechanic Properties of Polymer-Based Nanocomposites with Nanosilica by Nanoindentation. Journal of Reinforced Plastics and Composites. 2004; 23(13)1365-1372. http:// dx.doi.org/10.1177/0731684404037044

6. Zou H, Wi S and Shen J. Polymer/Silica Nanocomposites: Preparation, Characterization, Properties, and Applications. Chemical Reviews. 2008; 108:3893-3957. PMid:18720998. http://dx.doi.org/10.1021/cr068035q chains are strong enough to inhibit effective communication between the protons of the silica oxide nanoparticles, as already seen for other systems ${ }^{36}$.

\section{Conclusions}

The first analysis, by infrared spectroscopy, indicated there was binding between the PCL chain and modified silica oxide.

The DSC data showed that all the hybrids had lower Tc values and the crystallinity degree decreased for all the hybrid materials. Besides this, the XRD data showed that the PCL/Aerosil ${ }^{\circledR}$ R972 hybrids showed a broad amorphous halo stronger than the PCL/Aerosil ${ }^{\circledR}$ A200 hybrids, confirming that the hybrid materials have lower crystallinity degree than the PCL ${ }^{21}$.

The NMR relaxometry provided results related to the dispersion, interaction and structural organization of the hybrids. Direct measurements of proton $\mathrm{T}_{1} \mathrm{H}$ and $\mathrm{T}_{1} \rho \mathrm{H}$, using low-field NMR, proved to be a useful tool for the evaluation of polymer PCL/silica oxide hybrid systems. The data on both relaxation times were able to give information on the silica oxide dispersion in the polymer matrix, as well as the domain formation. According to the results, we can conclude that the method employed was efficient, rapid and practical for a better understanding the behavior of the hybrids formed.
7. Chrissafis K, Antoniadis G, Paraskevopoulus KM, Vassiliou A and Bikiaris DN. Comparative study of the effect of different nanoparticles on the mechanical properties and thermal degradation mechanism of in situ prepared poly( $\varepsilon$-caprolactone) nanocomposites. Composites Science and Technology. 2007; 67:2165-2174. http://dx.doi.org/10.1016/j. compscitech.2006.10.027

8. Ayala GG, Pace ED, Laurienzo P, Pantalena D, Somma E and Nobila MR. Poly( $\varepsilon$-caprolactone) modified by functional groups: Preparation and chemical-physical investigation. European Polymer Journal. 2009; 45(11):3217-3229. http:// dx.doi.org/10.1016/j.eurpolymj.2009.07.021

9. Ludueña LN, Alvarez VA and Vazquez A. Processing and microstructure of PCL/clay nanocomposites. Materials Science and Engineering: A. 2007; 460-461:121-129. http://dx.doi. org/10.1016/j.msea.2007.01.104

10. Tavares MIB, Nogueira RF, Gil RASS, Preto M, Silva EO, Silva MBR et al. Polypropylene-clay nanocomposite structure probed by H NMR relaxometry. Polymer Testing. 2007; 26:1100-1102. http://dx.doi.org/10.1016/j.polymertesting.2007.07.012

11. Sirelli L, Prado RMK, Tavares MIB, Nunes RCR and Dias ML. Molecular Dynamics of Poly(Ethylene Terephthalate)/Muscovite Mica Composite by Low-Field NMR. International Journal of Polymer Analysis and Characterization. 2008; 13:180-189. http://dx.doi.org/10.1080/10236660802070678

12. Freire E, Bianchi O, Forte MMC, Preto M, Monteiro EEC and Tavares MIB. Thermal and low-field NMR study on poly(vinylidene fluoride) and their physical mixtures with poly(methyl methacrylate). Polymer Engineering \& Science. 2008; 48:1901-1909. http://dx.doi.org/10.1002/ pen. 21174 
13. Rosa DS, Carvalho CL, Gaboardi F, Rezende ML, Tavares MIB, Petro MSM et al. Evaluation of enzymatic degradation based on the quantification of glucose in thermoplastic starch and its characterization by mechanical and morphological properties and NMR measurements. Polymer Testing. 2008; 27:827-834. http://dx.doi.org/10.1016/j.polymertesting.2008.06.008

14. Rodrigues TC, Tavares MIB, Preto M, Soares IL and Moreira ACF. Evaluation of Polyethylene/Organoclay Nanocomposites by Low-field Nuclear Relaxation. International Journal of Polymeric Materials. 2008; 57:1119-1123. http://dx.doi. org/10.1080/00914030802428716

15. Nogueira RF, Tavares MIB, San Gil RAS and da Silva NM. Solid state NMR investigation of polypropylene/Brazilian clay blending process. Polymer Testing. 2005; 24:358-362. http:// dx.doi.org/10.1016/j.polymertesting.2004.10.005

16. da Silva NM and Tavares MIB. Aplicação de Técnicas Combinadas de NMR no Estado Sólido para Avaliação do Sistema EPDM/PPa. Polímeros. 1994; 4:40-42.

17. Tang ZG, Black RA, Curran JM, Hunt JA, Rhodes NP and Williams DF. Surface properties and biocompatibility of solvent-cast poly[ $\varepsilon$-caprolactone] films. Biomaterials. 2004; 25:4741-4748. PMid:15120520. http:// dx.doi.org/10.1016/j.biomaterials.2003.12.003

18. Di Y, Iannace S, Di Maio E and Nicolais L. Nanocomposites by melt intercalation based on polycaprolactone and organoclay. Journal of Polymer Science Part B: Polymer Physics. 2003; 41:670-678. http://dx.doi.org/10.1002/ polb. 10420

19. Nakamoto K. Theory and applications in inorganic chemistry: Infrared and Raman Spectra of inorganic and coordination compound. 5th ed. John Wiley; 1997.

20. Nassar EJ, Messaddeq Y, Ribeiro SJL. Influência da catálise ácida e básica na preparação da sílica funcionalizada pelo método sol-gel. Química Nova. 2002; 25(1):27 http://dx.doi. org/10.1590/S0100-40422002000100006

21. Li R, Nie K, Shen X and Wang S. Biodegradable polyester hybrid nanocomposites containing titanium dioxide network and poly( $\varepsilon$-caprolactone): Synthesis and characterization. Materials Letters. 2007; 61:1368-1371. http://dx.doi. org/10.1016/j.matlet.2006.07.032

22. De Gaetano F, Ambrosio L, Raucci MG, Marotta A and Catauro M. Sol-gel processing of drug delivery materials and release kinetics. Journal of Materials Science: Materials in Medicine. 2005; 16:261-265. PMid:15744618. http://dx.doi. org/10.1007/s10856-005-6688-X

23. Prado AGS, Faria EA and Padilha PM. Aplicação e modificação química da sílica gel obtida de areia. Química Nova. 2005; 28(3):544. http://dx.doi.org/10.1590/ S0100-40422005000300030

24. Li R, Nie K, Pang W and Zhu Q. Morphology and properties of organic-inorganic hybrid materials involving $\mathrm{TiO}_{2}$ and poly( $\varepsilon$-caprolactone), a biodegradable aliphatic polyester. Journal of Biomedical Materials Research Part A. 2007; 83:114-122. PMid:17385234. http://dx.doi. org/10.1002/jbm.a.31224
25. Fukushima K, Tabuani D, Abbate C, Arena M and Rizzarelli P. Preparation, characterization and biodegradation of biopolymer nanocomposites based on fumed silica. European Polymer Journal. 2011; 47:139-152. http://dx.doi.org/10.1016/j. eurpolymj.2010.10.027

26. Fukushima K, Tabuani D and Camino G. Nanocomposites of PLA and PCL based on montmorillonite and sepiolite. Materials Science and Engineering: C. 2009; 29:1433-1441. http://dx.doi.org/10.1016/j.msec.2008.11.005

27. Sivalingam $\mathrm{G}$ and Madras G. Thermal degradation of binary physical mixtures and copolymers of poly( $\varepsilon$-caprolactone), poly(d, l-lactide), poly(glycolide). Polymer Degradation and Stability. 2004; 84:393-398. http://dx.doi.org/10.1016/j. polymdegradstab.2003.12.008

28. Draye AC, Persenaire O, Brožek J, Roda J, Košek T and Dubois $\mathrm{Ph}$. Thermogravimetric analysis of poly( $\varepsilon$-caprolactam) and poly[( $\varepsilon$-caprolactam)-co-( $\varepsilon$-caprolactone $)]$ polymers. Polymer. 2001; 42:8325-8332. http://dx.doi.org/10.1016/ S0032-3861(01)00352-4

29. Ray SS and Bousmina M. Biodegradable polymers and their layered silicate nanocomposites: In greening the 21 st century materials world. Progress in Materials Science. 2005; 50:962-1079. http://dx.doi.org/10.1016/j. pmatsci.2005.05.002

30. Liao L, Zhang C, Gong S. Preparation of Poly( $\varepsilon$-caprolactone)/ Clay Nanocomposites by Microwave-Assisted In Situ Ring-Opening Polymerization. Macromolecular Rapid Communications. 2007; 28:1148-1154. http://dx.doi. org/10.1002/marc.200700063

31. Tavares MIB, Ferreira O, Preto MSM, Miguez E, Soares IL and Silva EP. Evaluation of Composites Miscibility by Low Field NMR. International Journal of Polymeric Materials. 2007; 56(4):1113-1118. http://dx.doi. org/10.1080/00914030701283063

32. Bruno M, Tavares MIB, Motta LM, Miguez E, Preto M and Fernandez AOR. Evaluation of PHB/Clay nanocomposite by spin-lattice relaxation time. Materials Research. 2008; 4:483. http://dx.doi.org/10.1590/S1516-14392008000400018

33. Preto M, Tavares MIB and Silva EP. Low-field NMR study of Nylon 6/silica composites. Polymer Testing. 2007; 26:501-504. http://dx.doi.org/10.1016/j.polymertesting.2007.01.009

34. Hayashi $\mathrm{S}$ and $\mathrm{Omi} \mathrm{H}$. Proton diffusion in the room-temperature phase of $\left[\left(\mathrm{NH}_{4}\right)_{1-\mathrm{x}} \mathrm{Rb}_{\mathrm{x}}\right]_{3} \mathrm{H}\left(\mathrm{SO}_{4}\right)_{2}$ as studied by ${ }^{1} \mathrm{H}$ spin-lattice relaxation in the rotating fram. Solid State Nuclear Magnetic Resonance. 2010; 37:69-74. PMid:20627482. http://dx.doi. org/10.1016/j.ssnmr.2010.05.002e

35. Arantes TM, Leão KV, Tavares MIB, Ferreira AG, Longo E and Camargo ER. NMR study of styrene-butadiene rubber (SBR) and $\mathrm{TiO}_{2}$ nanocomposites. Polymer Test. 2009; 28:490-494. http://dx.doi.org/10.1016/j.polymertesting.2009.03.011

36. Kwak SY and Kim SY. Microphase structures of polymers containing structural heterogeneity as probed by n.m.r. spin-lattice relaxation analysis. Polymer. 1998; 39(17):4099-4105. http:// dx.doi.org/10.1016/S0032-3861(97)10229-4 